\title{
Near-Field Measurements of Water-Entry Sound of Low-Speed Metal Balls in a Non-Anechoic Tank
}

\author{
Qi Li, ${ }^{1,2,3}$ Yihan Yang $\mathbb{D}^{1,2,3}$ Dajing Shang $\mathbb{D}^{1,2,3}$ Rui Tang, ${ }^{1,2,3}$ and Fangzhou Deng ${ }^{1,2,3}$ \\ ${ }^{1}$ Acoustic Science and Technology Laboratory, Harbin Engineering University, Harbin 150001, China \\ ${ }^{2}$ Key Laboratory of Marine Information Acquisition and Security, Harbin Engineering University, \\ Ministry of Industry and Information Technology, Harbin 150001, China \\ ${ }^{3}$ College of Underwater Acoustic Engineering, Harbin Engineering University, Harbin 150001, China \\ Correspondence should be addressed to Dajing Shang; shangdajing@hrbeu.edu.cn
}

Received 18 May 2021; Revised 10 July 2021; Accepted 15 July 2021; Published 31 August 2021

Academic Editor: Yang Li

Copyright (c) 2021 Qi Li et al. This is an open access article distributed under the Creative Commons Attribution License, which permits unrestricted use, distribution, and reproduction in any medium, provided the original work is properly cited.

\begin{abstract}
As one of the target characteristics, water-entry sound characteristics are of great significance to study, and its research has certain reference value for the detection of sea target. The water-entry sound of an underwater target is a transient sound signal, and it is mainly measured in open water such as the sea and lakes. However, due to the short duration of the acoustic signal and the modulation effect of the measuring environment, it is difficult to measure water-entry sound. To deal with this problem, in this work, the water-entry sound of a metal ball was measured in a water tank in a laboratory. The measurements were made in the direct acoustic control area $0.45 \mathrm{~m}$ away from the drop point of the ball to eliminate the influence of reflection. Through a timedomain integration, the power of the transient signal of the water-entry sound of the metal ball was obtained. The energy of the initial impact sound and the pulsating-bubble sound was investigated, as was the impact of ball size, entry velocity, and other factors on the characteristics of the water-entry sound. The results show that by combining the virtual-source method with the time-domain integral in the near field, the energy of the incoming sound can be obtained accurately. The results are consistent with closed-space measurements. The water-entry sound includes the initial impact sound and the pulsating-bubble sound. The energy of the pulsating-bubble sound is $3-5$ orders of magnitude larger than that of the initial impact sound. The average power level of the water-entry sound is proportional to the ball size and the $2 / 3$ power of the slamming velocity. The relation between the average power level and the $1 / 3$ power of the kinetic energy is an exponential function with base 10. Based on the kinetic energy variety of metal balls entering the water, an acoustic model of this system is established. The results can be used for reference to other transient sound measurements.
\end{abstract}

\section{Introduction}

The phenomenon of objects entering the water is common in our life, such as the airdrop of torpedoes, raindrops landing on the sea, and lifeboats being dropped from a ship [1,2], which is a complex physical process with important research significance. When an object enters a body of water, the transient acoustic signals will be generated. The object carries air into the water, which forms a cavity behind it. The larger the cavity, the larger the size and frequency range of the bubbles. The sound energy generated radiates to the surrounding area [3].

In the early years, scientists focused on air conduction based on the interactions between a two-dimensional rigid body and an ideal liquid. In 1900, Worthington undertook many insightful and systematic studies on objects entering the water. He took photographs of metal balls entering water using the flash photography technology of the time. These show the flow of liquid around the metal balls, the formation of a cavity, and the splash [4]. Some of Worthington's photographs of a metal ball falling into water are shown in Figure 1.

Following Worthington's experiments, in 1918, Mallock studied the sound field induced by the underwater motion of an object as it enters the water through a large number of experiments [5]. In 1924, Bell conducted research into a sphere entering water vertically, laying the foundations for 
Fig. 1.

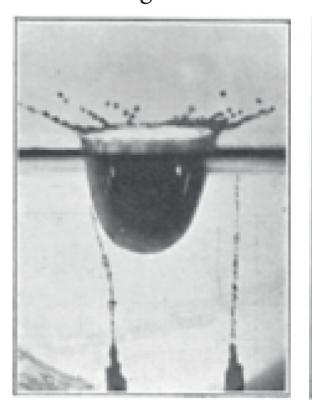

Fig. 5 .

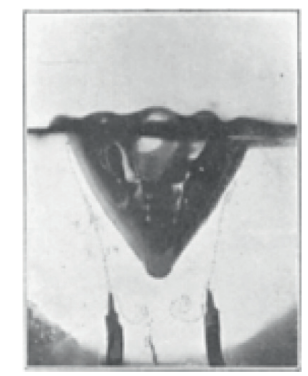

FIGURE 1: Worthington's photographs of a metal ball entering water [4].
Fig. 3.

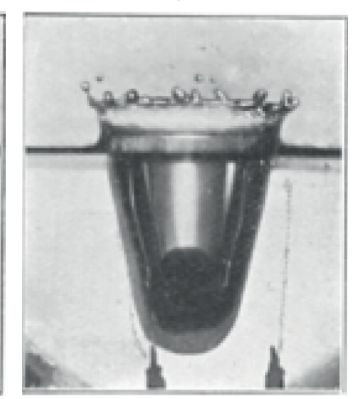

Fig. 6.

\section{.}

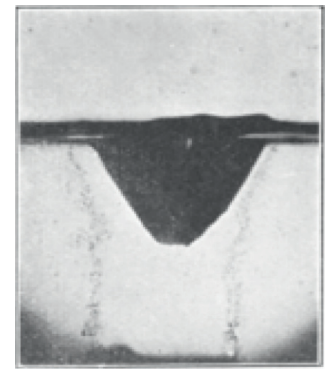

Fig. 2.

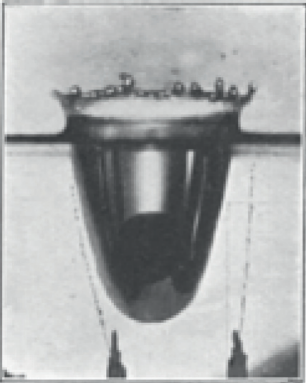

$$
\text { . }
$$


The water-entry sound mainly includes an initial impact sound and a pulsating-bubble sound (as shown in Figure 2). As can be seen from the figure, both the amplitude of the sound pressure and the duration of the initial impact sound are much lower than for the pulsating-bubble sound. The initial impact sound signal is very short, so that it is a transient sound signal. A pulsating-bubble sound signal is a damped oscillation with, usually, a long duration.

It is assumed that when an object enters water, the water surface remains horizontal and the signal of the water-entry sound is equivalent to a radiation sound source. For a nonanechoic tank [17],

$$
p^{2}=W \rho_{0} c_{0}\left(\frac{1}{4 \pi r^{2}}+\frac{4}{R}\right)
$$

where $p$ is the sound pressure, $W$ is the sound power, $\rho_{0} c_{0}$ is the characteristic impedance of water, $r$ is the distance from the measuring point to the sound source, and $R$ is a constant for the pool. Here, $R=S \bar{\alpha} /(1-\bar{\alpha})$, where $S$ is the total area of the wall of the tank and $\bar{\alpha}$ is the average sound absorption coefficient of the wall of the tank. In equation (1), the first term represents the contribution of direct sound and the second represents the contribution of reverberated sound. When the two are equal, $r=r_{h}$, so the reverberation radius is as follows:

$$
r_{h}=\frac{1}{4} \sqrt{\frac{R}{\pi}}
$$

When $r \ll r_{h}$, direct sound plays the main role, and reverberated sound can be ignored, so that

$$
p^{2}=W \rho_{0} c_{0} \frac{1}{4 \pi r^{2}} \text {. }
$$

For sound measured by a hydrophone in the near field, the distance from the drop point to the hydrophone is the Rayleigh distance:

$$
d=\frac{a^{2}}{\lambda}=\frac{a^{2}}{c / f_{0}}=\frac{a^{2} f_{0}}{c}
$$

where $\lambda$ is the wavelength of the sound wave. If the experimental research frequency band exceeds the calculated frequency $f_{0}$, the far-field condition is not satisfied and the measured value is not accurate. The frequency $f_{0}$ is

$$
f_{0}=\frac{d c}{a^{2}}=\frac{\sqrt{1+L^{2}} c}{a^{2}}=\frac{\sqrt{1+0.45^{2}} \times 1500}{0.007^{2}}=3.36 \times 10^{7} \mathrm{~Hz}
$$

where $a=0.007 \mathrm{~m}$ is the radius of the ball, $L=0.45 \mathrm{~m}$ is the horizontal measurement distance, $d$ is the Rayleigh distance (the distance from the hydrophone to the drop point), and $c$ is the speed of sound in water. All physical quantities are in SI units. Here, $f_{0}$ is far larger than the frequency range studied in the experiment, so the signals in the frequency band $0-20 \mathrm{kHz}$ measured in the near field meet the far-field conditions.

When a metal ball falls into water and the incoming sound is measured very close to the water surface, the virtual-source method can be used to approximate the radiation sound field as it is almost a dipole sound field [18], as shown in Figure 3.

The distance between the two sound sources is $d_{0}$, the distance from the point $M$ to the center of the sound source is $r$, and the distances from the sound sources 1 and 2 are $r_{+}$ and $r_{-}$, respectively. The total velocity potential of the twopoint sources at point $M$ is

$$
\begin{aligned}
\Phi(r, \theta, t) & =\Phi_{+}(r, \theta, t)+\Phi_{-}(r, \theta, t)=\frac{Q}{4 \pi r_{+}}\left(e^{-j k r_{+}}+e^{j k r_{-}}\right) e^{j \omega t} \\
& =-\frac{Q_{1}}{4 \pi} \frac{\partial}{\partial r}\left(\frac{e^{-j k r}}{r}\right) \cos \theta e^{j \omega t}(r \gg d),
\end{aligned}
$$

where $Q_{1} \equiv Q d_{0}$ is the dipole moment. The sound pressure function for the acoustic dipole is

$$
\begin{aligned}
p(r, \theta, t) & =\rho \frac{\partial}{\partial r} \Phi(r, \theta, t)=j \omega \rho \Phi(r, \theta, t) \\
& =\frac{j k \rho c Q_{1}}{4 \pi r^{2}} \sqrt{1+(k r)^{2}} \cos \theta e^{j(\omega t-k r+\varphi)},
\end{aligned}
$$

where $\varphi$ satisfies $\operatorname{tg} \varphi=k r$. The particle velocity of an acoustic dipole consists of two components, $r$ and $\theta$. Using $\vec{u}(r, \theta, t)=-\nabla \Phi(r, \theta, t)$, the components of the particle velocity $u_{r}$ and $u_{\theta}$ in the radial and perpendicular directions are

$$
\begin{aligned}
& u_{r}(r, \theta, t)=-\frac{\partial}{\partial r} \Phi(r, \theta, t)=\frac{Q_{1}}{4 \pi} \frac{\sqrt{4+(k r)^{4}}}{r^{3}} \cos \theta e^{j\left(\omega t-k r+\varphi^{\prime}\right)}, \\
& u_{\theta}(r, \theta, t)=-\frac{\partial \varphi}{\partial(r \theta)}=-\frac{\partial \varphi}{r \partial(\theta)}=-\frac{Q_{1} e^{j(\omega t-k r+\varphi)}}{4 \pi r^{3}} \sqrt{1+(k r)^{2}} \sin \theta
\end{aligned}
$$

Since $r \gg d$, the expressions for the far-field sound pressure and particle velocity can be further simplified. Using equations (7)-(9) and the far-field conditions gives

$$
\begin{aligned}
& p(r, \theta, t) \approx-\frac{Q_{1}}{4 \pi r} k^{2} \rho c \cos \theta e^{j(\omega t-k r)}, \\
& u_{r}(r, \theta, t) \approx-\frac{Q_{1}}{4 \pi r} k^{2} \cos \theta e^{j(\omega t-k r)}=\frac{p(r, \theta, t)}{\rho c}, \\
& u_{\theta}(r, \theta, t)=\frac{Q_{1}}{4 \pi r^{2}} k \sin \theta e^{j(\omega t-k r+(\pi / 2))} .
\end{aligned}
$$

Using equations (11) and (12), the radial and perpendicular components of the radial sound intensity for the far field are

$$
\begin{aligned}
& I_{r}(r, \theta)=\frac{1}{T} \int_{0}^{T} \vec{\omega}_{r}(r, \theta, t) \mathrm{d} t=\frac{1}{2 \rho c}\left(\frac{Q_{1}}{4 \pi r} k^{2} \cos \theta \rho c\right)^{2}, \\
& I_{\theta}(r, \theta)=\frac{1}{T} \int_{0}^{T} \vec{\omega}_{\theta}(r, \theta, t) \mathrm{d} t=0,
\end{aligned}
$$




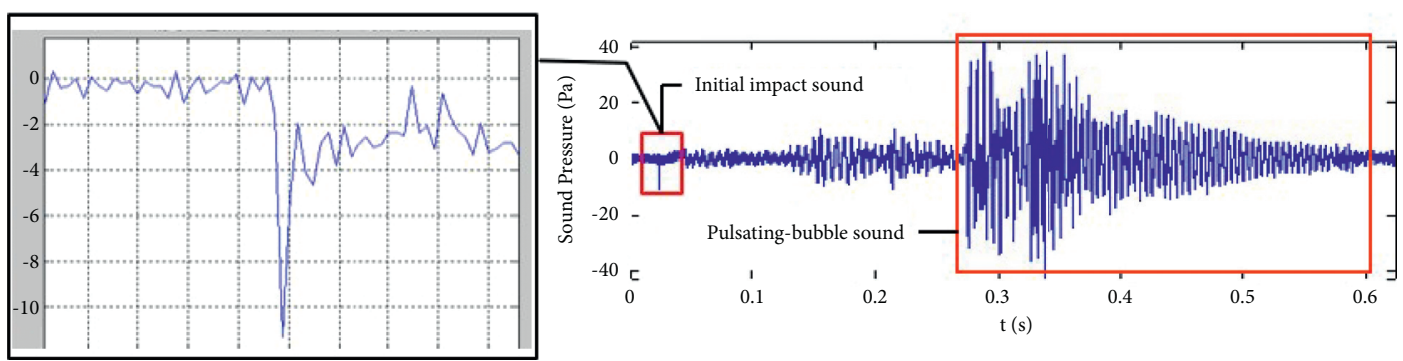

Figure 2: Sound signal in the time domain.

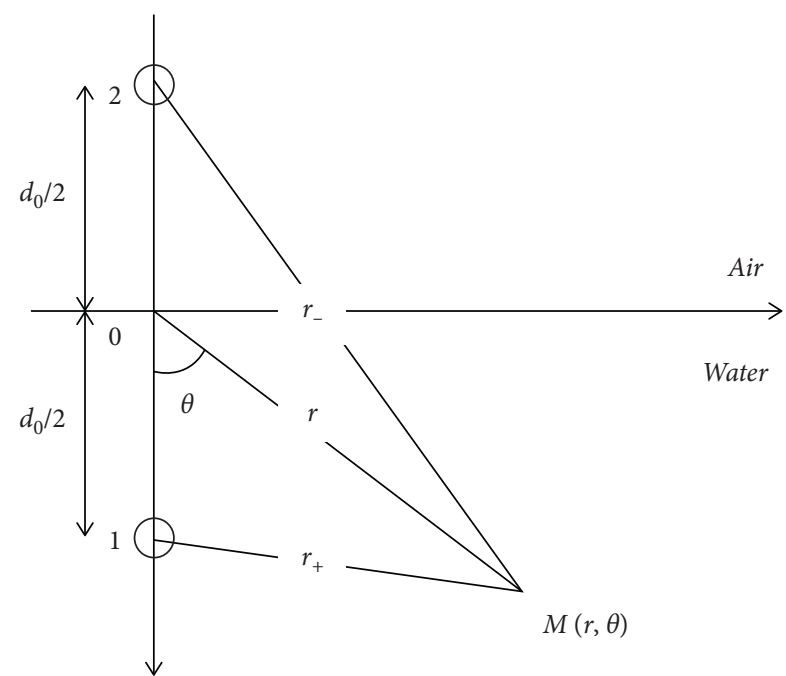

FIGURE 3: Schematic diagram of the virtual-source method for an object entering water.

where $\vec{\omega}(r, \theta, t)=\operatorname{Re}[p(r, \theta, t)] \operatorname{Re}[u(r, \theta, t)]$. Thus,

$$
I(r, \theta)=I_{r}(r, \theta)=\frac{\rho c}{2}\left(\frac{Q_{1}}{4 \pi} k^{2}\right)^{2} \frac{1}{r^{2}} \cos ^{2} \theta .
$$

According to the formula for the total sound intensity, the radiation sound power and sound power level of the dipole sound source can be calculated as

$$
\begin{aligned}
W & =\iint_{S} \operatorname{Ir} \sin \theta \mathrm{d} \theta=2 \pi \frac{\rho c}{2}\left(\frac{Q_{1}}{4 \pi} k^{2}\right)^{2} \frac{2}{3}, \\
L_{W} & =10 \log \left(\frac{W}{W_{\text {ref }}}\right), \\
W_{\text {ref }} & =0.67 \times 10^{-18} \mathrm{~W} .
\end{aligned}
$$

2.2. Calculation of Bubble Radius. When an object enters water, it produces many bubbles. These have a range of sizes, which affects the pulsating-bubble part of the sound signal. There is a functional relationship between the equivalent radius of a bubble and its resonance frequency. It is assumed that the bubbles generated by a solid steel ball entering water at a low speed are approximately spherical and ideal. The relationship between their equivalent radius and resonance frequency is

$$
a_{0}=\frac{1}{2 \pi f} \sqrt{\frac{3 \gamma P_{0}}{\rho_{0}}},
$$

where $f$ is the resonance frequency of the bubble, $a_{0}$ is the radius of the bubble, and $\gamma$ is the specific heat ratio of air, which is generally assumed to be $\gamma=1.4 . P_{0}$ is the local pressure at the hydrophone.

\section{Experiments and Methods}

The experiment was carried out in the non-anechoic tank of the Key Laboratory of Underwater Acoustic Technology of Harbin Engineering University.

3.1. Experimental Measuring System. The experimental system is shown in Figure 4. The length, width, and height of the pool are $15 \mathrm{~m}, 9.3 \mathrm{~m}$, and $6 \mathrm{~m}$, respectively. The walls and floor of the pool are covered with ceramic tiles. The reverberation radius of the pool corresponding to the study frequency is $r_{h}=1.7 \mathrm{~m}$ [17]. The main parts of the equipment used in the experiment included the PULSE data collector, a 8103 hydrophone, a release device with an adjustable height (which has a support frame, lifting rod, release rod, and lifting and adjusting knobs, as shown in Figure 5), and a net.

During the experiment, the hydrophone was approximately at the same height as the drop point of the ball, and the horizontal distance from the metal ball was $0.45 \mathrm{~m}$, which allowed the hydrophone to collect clear signals with a high signal-to-noise ratio. The distance between the drop point and the hydrophone was much less than the reverberation radius, and the influence of sound reflected from the walls of the tank can be ignored. To prevent the ball from hitting the bottom of the tank and making a noise, the ball was caught by a net fixed at a depth of 2-3 $\mathrm{m}$ as a recovery device.

3.2. Experimental Method. According to the scale effect in fluid mechanics, the size of the ball itself has little effect on the surrounding fluid. For a constant entry velocity and fixed experimental conditions, the initial impact sound and pulsating-bubble sound depend on the size of the ball. In contrast, if the size of the steel ball remains unchanged, the initial impact sound and pulsating-bubble sound depend on the entry velocity. According to Newton's second law, the entry velocity can be calculated using $v=\sqrt{2 g H}$. 


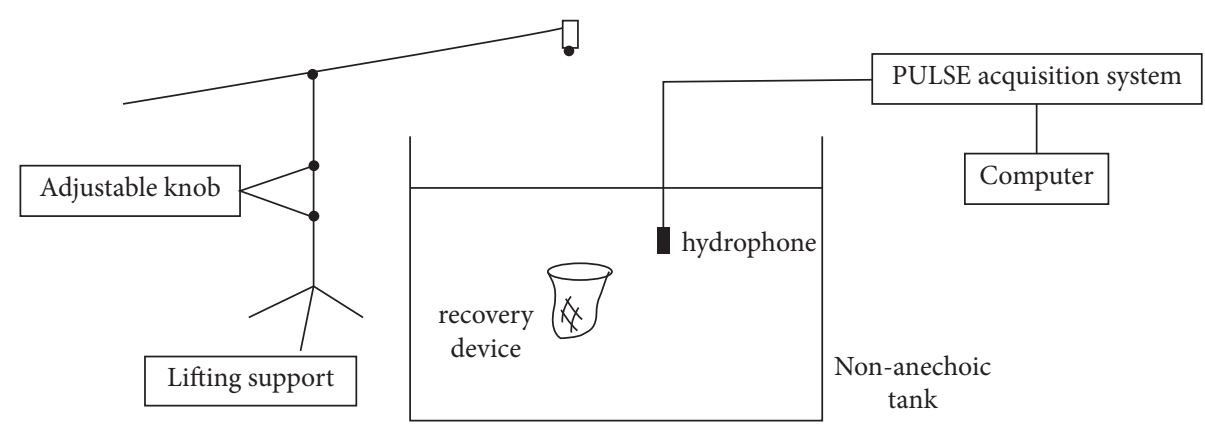

FIgURE 4: Schematic diagram of the experimental measurement system.

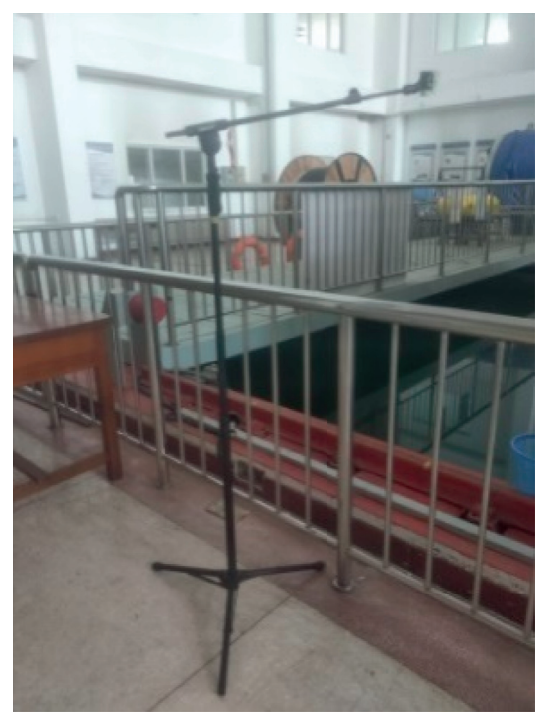

FIgURE 5: Photograph of the release device.

After the sound pressure was experimentally obtained, the sound power level was calculated according to equation (16), and the power spectrum of the pulsating-bubble sound was used to obtain the range of the bubble resonance frequency. The corresponding range for the bubble radius was then calculated according to equation (17).

Before the experiment began, the accuracy of the experimental method was verified. According to the method described in references $[17,19]$ a transient acoustic signal can be measured in a closed space. The water-entry sound power is then obtained using a spatial average. In the experiment, four hydrophone arrays were each arranged in a U-shaped layout in the control area of the reverberation sound, as shown in Figure 6. Each line array of hydrophones is $8 \mathrm{~m}$ long with 30 hydrophones. The distance between each hydrophone array and the sound source is sufficient to meet the far-field conditions, as much as possible.

Each experiment collected data for $5 \mathrm{~s}$ and was repeated at least 30 times to ensure the accuracy of the results. The signals collected by the hydrophone were processed by the PULSE collector, which read the data, isolated the initial impact sound and pulsating-bubble sound for further analysis and processing, and determined the sound pressure, sound power, and other physical quantities. MATLAB was then used to process the data using the near-field virtualsource time-domain integration method to obtain a timedomain image of the sound signal. A power law was fitted to the data collected in the experiments. Three experiments were run to measure the sound of metal balls entering water, as listed in Table 1.

\section{Results}

4.1. Eliminating Reflected Sound in Near-Field Experiments. The data obtained from the transient sound measurements in the far field of the closed space were compared with those obtained by the near-field virtual-source time-domain integration method with a virtual source in the near field (taking the pulsating-bubble sound, as an example). When transient sound is measured in a closed space, the direct sound and reflected sound are superimposed on each other due to reflections from the walls, so it is difficult to identify the characteristics of the sound signal, as shown in Figure 7. Moreover, the signal duration is longer than for near-field measurements. Thus, near-field measurements were used to eliminate the influence of the reflected sound in the time domain.

4.2. Verification of Measurement Methods. The near-field virtual-source time-domain integration method and the farfield closed-space method were used to measure the transient noise $[17,19]$. The results are shown in Table 2 . It can be seen from the data in the table that the differences between the power level of water-entry sound obtained by the timedomain integration method for a near-field virtual source and the reverberation method are less than $1 \mathrm{~dB}$.

\subsection{Experiment 1: Different Ball Sizes for the Same Entry} Velocity. The experimental method described in Section 3.1 can be used to measure the pressure of the initial impact sound and pulsating-bubble sound for different sizes of the metal ball. The method described in Section 2.1 can then be used to calculate the power level for the initial impact sound (Figure 8) and the pulsating-bubble sound (Figure 9). The data points were fitted to linear relations:

$$
\begin{aligned}
& L_{W_{1}}=6.8 \times 10^{2} D+1.3 \times 10^{2}, \\
& L_{W_{2}}=1.7 \times 10^{3} D+1.3 \times 10^{2},
\end{aligned}
$$




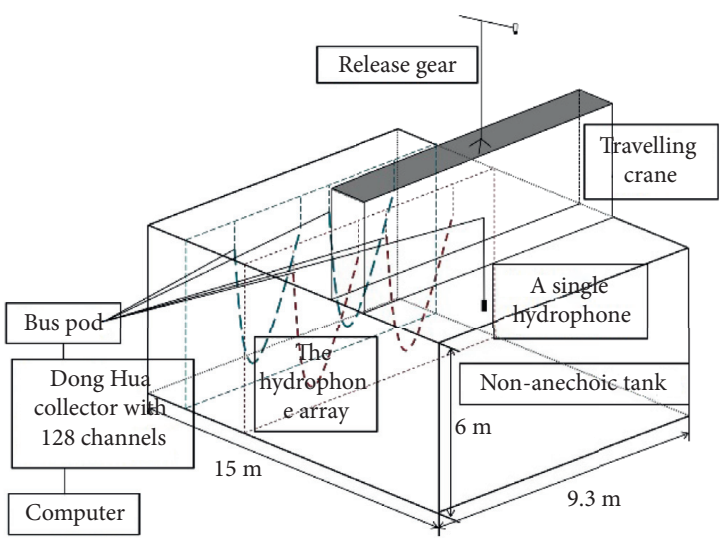

(a)

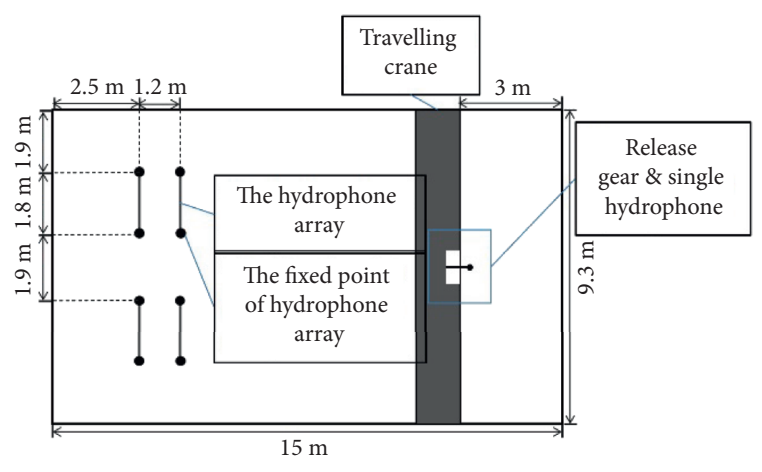

(b)

FiguRE 6: Water-entry sound measurement system based on the spatial average in the non-anechoic tank: (a) stereogram and (b) planform.

TABle 1: Experimental conditions.

\begin{tabular}{|c|c|c|}
\hline Experiment & Working conditions & Parameters \\
\hline 1 & Virtual-source integration in time domain for near-field validation & $\begin{array}{c}\text { Entry angle } \theta=90^{\circ} \\
\text { Horizontal measuring distance } L=0.45 \mathrm{~m} \\
\text { Entry speed } v=9.02 \mathrm{~m} / \mathrm{s} \\
\text { Ball size } D=6,8,10,12 \mathrm{~mm}\end{array}$ \\
\hline 2 & Fixed ball size, different entry speeds in near-field & $\begin{array}{c}\text { Ball size } D=8 \mathrm{~mm} \\
\text { Entry speed } v=5.89,6.37,6.82,7.14,7.54,7.92 \mathrm{~m} / \mathrm{s} \\
\text { Entry angle } \theta=90^{\circ} \\
\text { Horizontal measuring distance } L=0.45 \mathrm{~m}\end{array}$ \\
\hline 3 & Fixed entry speed, different ball sizes in near-field & $\begin{array}{c}\text { Ball size } D=4,6,8,10,12,14,16,18,20 \mathrm{~mm} \\
\text { Entry speed } v=5.89 \mathrm{~m} / \mathrm{s} \\
\text { Entry angle } \theta=90^{\circ} \\
\text { Horizontal measuring distance } L=0.45 \mathrm{~m}\end{array}$ \\
\hline
\end{tabular}
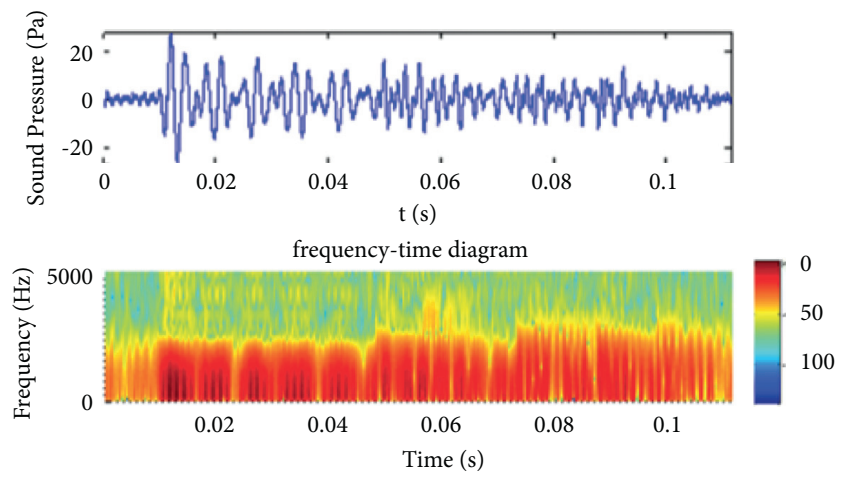

(a)

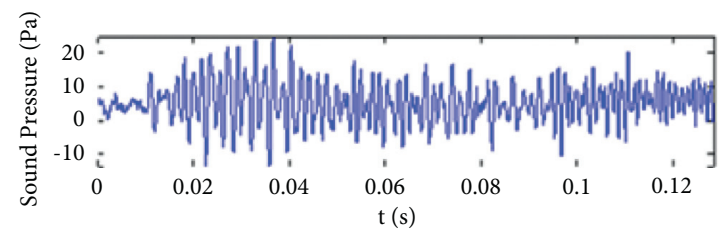

frequency-time diagram

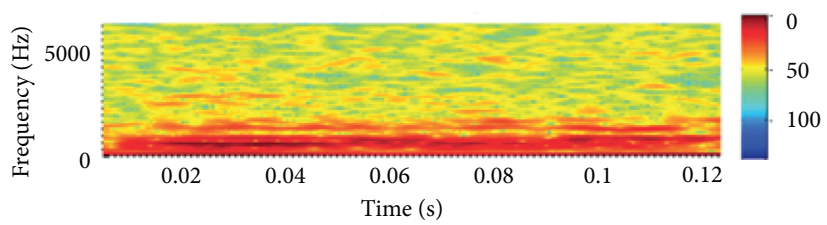

(b)

Figure 7: Measurement of water-entry sound: (a) near-field virtual-source time-domain integration and (b) far-field closed-space measurement.

$R^{2}$ is the ratio of the regression sum of squares to the total sum of squares. The closer it is to 1 , the better the fit is.

Table 3 shows that the energy conversion rate for the initial impact sound is much lower than that for the pulsating-bubble sound, about 3-5 orders of magnitude. Alternatively, the conversion efficiency relative to the kinetic energy was the same for both types of sound. Thus, the kinetic energy of the ball is partly converted into initial 
TABLE 2: Measurements of water-entry sound.

\begin{tabular}{lccr}
\hline \multicolumn{2}{c}{$\begin{array}{c}\text { Far-field closed-space measurements } \\
\text { Kinetic energy }(\mathrm{J})\end{array}$} & \multicolumn{2}{c}{ Near-field virtual-source time-domain integration } \\
Sound power level $(\mathrm{dB})$ & 142.6 & 0.1901 & 143.1 \\
0.1901 & 147.4 & 0.4506 & 147.1 \\
0.4506 & 151.7 & 0.8801 & 151.1 \\
0.8801 & 155.5 & 1.5208 & 155.0 \\
1.5208 & Kinetic energy $(\mathrm{J})$ & power level $(\mathrm{dB})$ \\
\hline
\end{tabular}

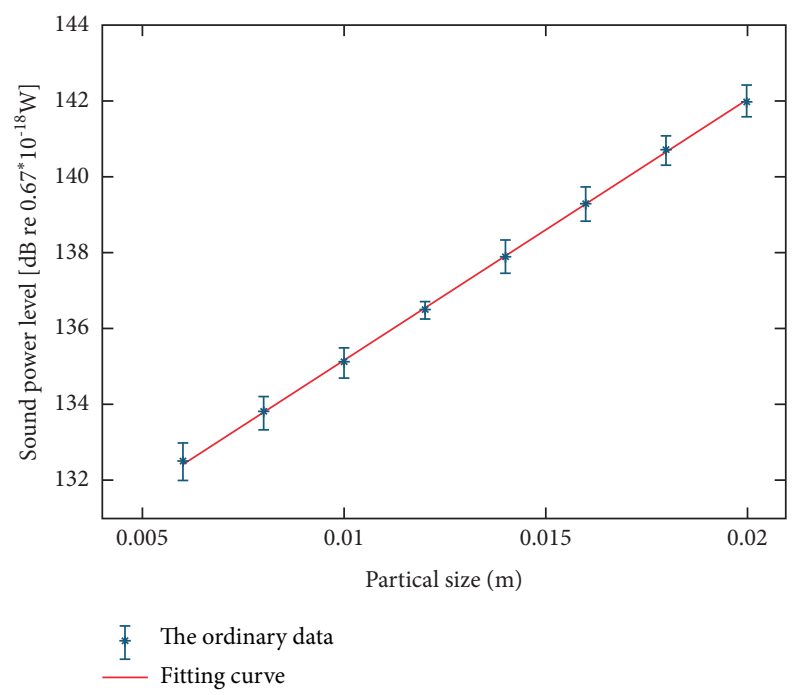

FIGURE 8: Initial impact sound power level versus ball size.

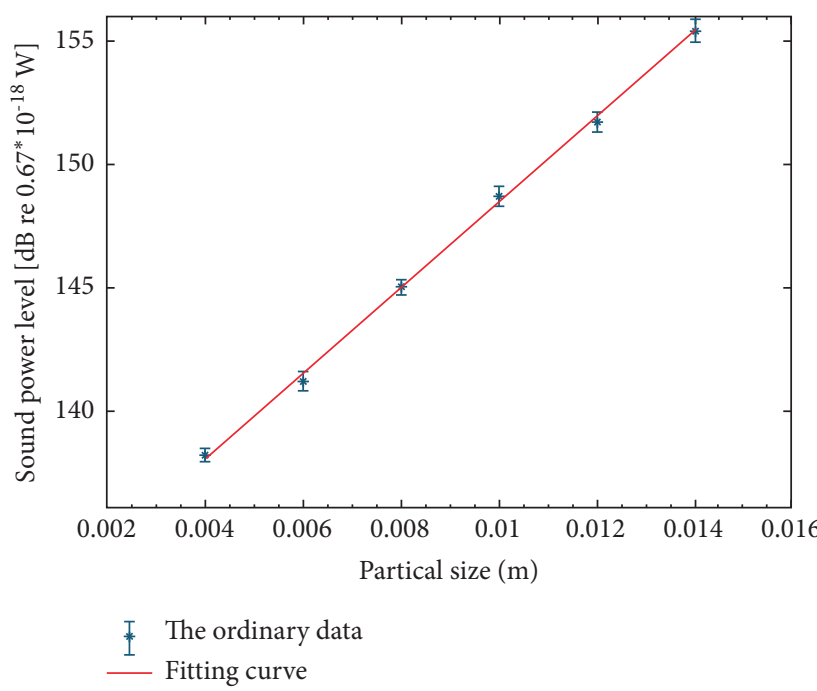

Figure 9: Pulsating-bubble sound power level versus ball size.

impact sound and pulsating-bubble sound but mainly remains as kinetic energy since the ball continues to move.

4.4. Experiment 2: Different Entry Velocities for the Same Ball Size. As above, the power level was calculated for the initial impact sound (Figure 10) and the pulsating-bubble sound (Figure 11) for different entry velocities. These were plotted against $v^{2 / 3}$. The fitted power laws are

$$
\begin{aligned}
& L_{W_{3}}=1.509 \times v^{2 / 3}+128.9, \\
& L_{W_{4}}=4.708 \times v^{2 / 3}+129.6 .
\end{aligned}
$$

Table 4 shows that there is a difference of about 4 orders of magnitude between the energy conversion rates for the initial impact sound and the pulsating-bubble sound. As before, the kinetic energy is mainly not converted as the ball continues to move.

\subsection{Acoustic Model of Water-Entry Sound}

4.5.1. Relations between Sound Power Level and Kinetic Energy. The results in Sections 4.3 and 4.4 can be converted and combined to kinetic energy (Figures 12 and 13 ). Thus, the model of underwater sound is established. The unified power laws are then

$$
\begin{aligned}
& L_{W_{5}}=8.289 \times E_{k}^{1 / 3}+128.2, \\
& L_{W_{6}}=20.85 \times E_{k}^{1 / 3}+131.1 .
\end{aligned}
$$

4.5.2. Relation between Bubble Radius and Kinetic Energy. Figure 14 shows the power spectrum for the pulsatingbubble sound (red) and the background sound (black). According to equation (17), the range of the bubble radius depends on the resonance frequency of the bubble. In 
TABLE 3: Water-entry sound energy corresponding to each ball size.

\begin{tabular}{lccccc}
\hline $\begin{array}{l}\text { Ball size } \\
(\mathrm{m})\end{array}$ & $\begin{array}{c}\text { Kinetic } \\
\text { energy }(\mathrm{J})\end{array}$ & $\begin{array}{c}\text { Initial impact sound } \\
\text { energy }(\mathrm{J})\end{array}$ & $\begin{array}{c}\text { Initial impact energy } \\
\text { conversion rate }(\%)\end{array}$ & $\begin{array}{c}\text { Pulsating-bubble } \\
\text { sound energy }(\mathrm{J})\end{array}$ & $\begin{array}{c}\text { Pulsating-bubble sound energy } \\
\text { conversion rate }(\%)\end{array}$ \\
\hline 0.006 & 0.1243 & $2.10 \times 10^{-10}$ & $1.69 \times 10^{-7}$ & $9.84 \times 10^{-7}$ & $7.91 \times 10^{-4}$ \\
0.008 & 0.2937 & $2.19 \times 10^{-10}$ & $7.46 \times 10^{-8}$ & $1.87 \times 10^{-6}$ & $6.34 \times 10^{-4}$ \\
0.010 & 0.5757 & $3.59 \times 10^{-10}$ & $6.24 \times 10^{-8}$ & $3.95 \times 10^{-6}$ & $6.86 \times 10^{-4}$ \\
0.012 & 0.9947 & $4.79 \times 10^{-10}$ & $4.82 \times 10^{-8}$ & $8.98 \times 10^{-6}$ & $9.03 \times 10^{-4}$ \\
0.014 & 1.5796 & $8.32 \times 10^{-10}$ & $5.27 \times 10^{-8}$ & $2.42 \times 10^{-5}$ & $1.53 \times 10^{-3}$ \\
\hline
\end{tabular}

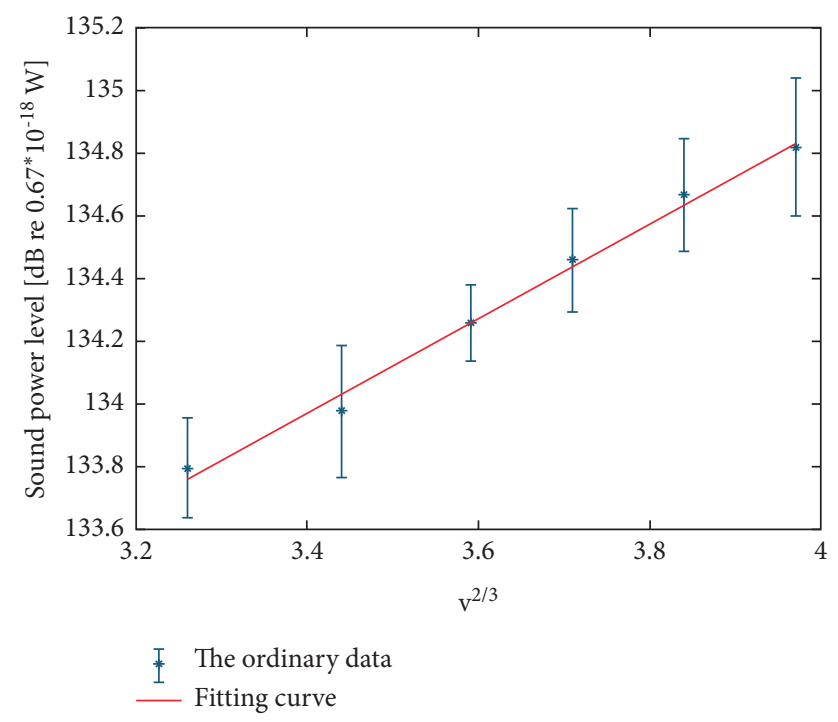

FIgURE 10: Initial impact sound power level versus $v^{2 / 3}$.

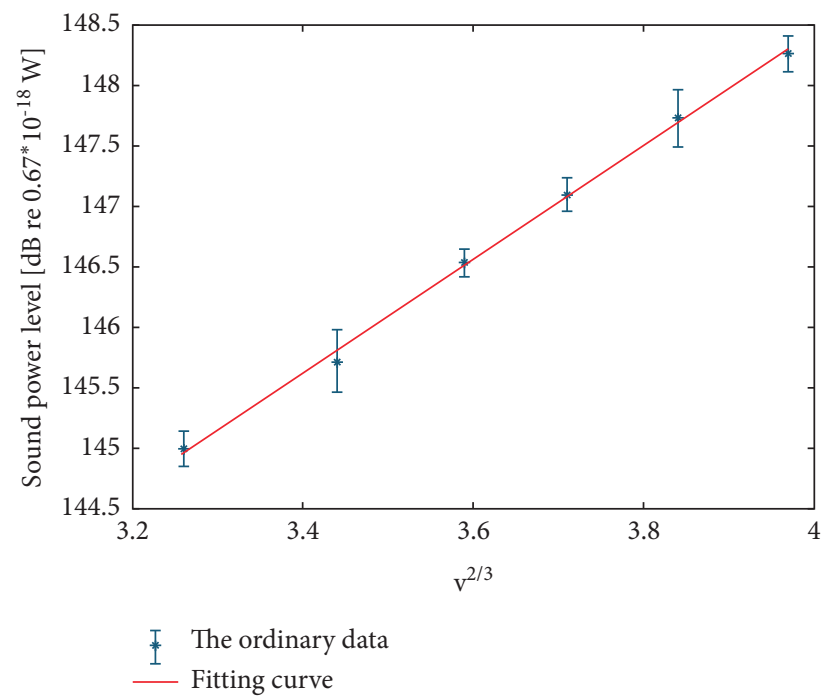

Figure 11: Pulsating-bubble sound power level versus $v^{2 / 3}$.

TABLE 4: Water-entry sound energy for each entry velocity.

\begin{tabular}{lccccc}
\hline $\begin{array}{l}\text { Entry velocity } \\
(\mathrm{m} / \mathrm{s})\end{array}$ & $\begin{array}{c}\text { Kinetic } \\
\text { energy }(\mathrm{J})\end{array}$ & $\begin{array}{c}\text { Initial impact sound } \\
\text { energy }(\mathrm{J})\end{array}$ & $\begin{array}{c}\text { Initial impact energy } \\
\text { conversion rate }(\%)\end{array}$ & $\begin{array}{c}\text { Pulsating-bubble } \\
\text { sound energy }(\mathrm{J})\end{array}$ & $\begin{array}{c}\text { Pulsating-bubble sound energy } \\
\text { conversion rate }(\%)\end{array}$ \\
\hline 5.89 & 0.2937 & $2.78 \times 10^{-10}$ & $9.46 \times 10^{-8}$ & $1.87 \times 10^{-6}$ & $6.37 \times 10^{-4}$ \\
6.37 & 0.3435 & $3.31 \times 10^{-10}$ & $9.62 \times 10^{-8}$ & $2.57 \times 10^{-6}$ & $7.47 \times 10^{-4}$ \\
6.82 & 0.3933 & $3.96 \times 10^{-10}$ & $1.01 \times 10^{-7}$ & $3.42 \times 10^{-6}$ & $8.71 \times 10^{-4}$ \\
7.14 & 0.4315 & $4.46 \times 10^{-10}$ & $1.03 \times 10^{-7}$ & $4.23 \times 10^{-6}$ & $9.81 \times 10^{-4}$ \\
7.54 & 0.4813 & $5.23 \times 10^{-10}$ & $1.09 \times 10^{-7}$ & $5.47 \times 10^{-6}$ & $1.14 \times 10^{-3}$ \\
\hline
\end{tabular}




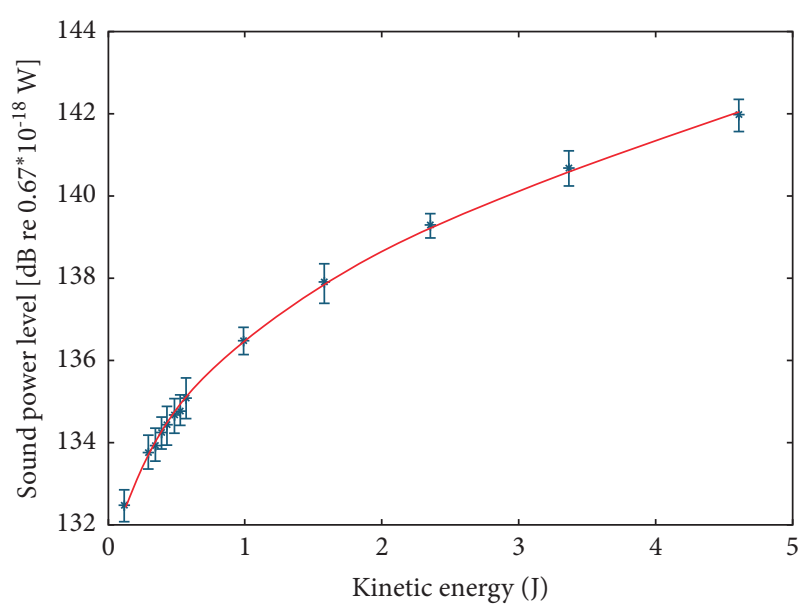

平 The ordinary data

FIGURE 12: Initial impact sound power level versus entry kinetic energy.

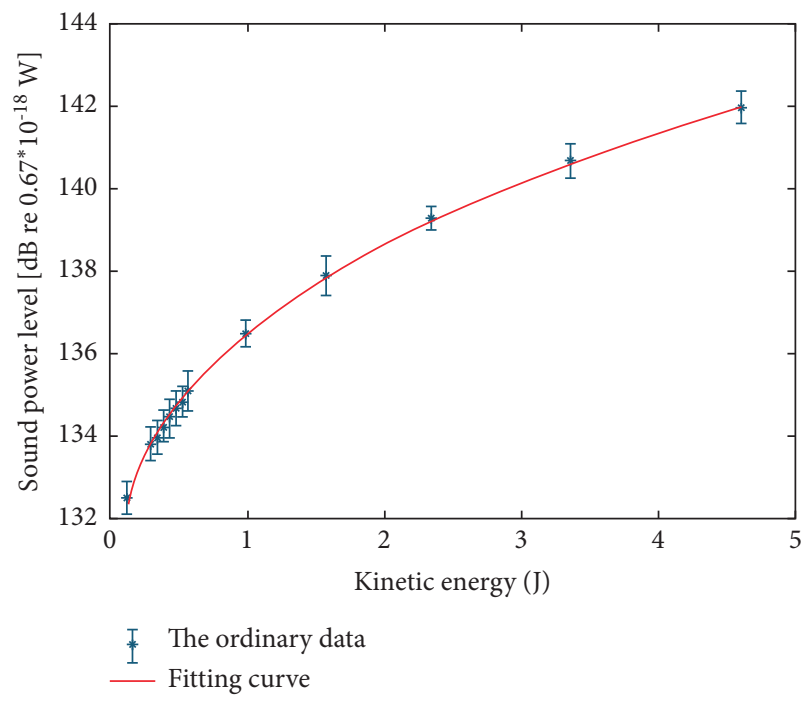

FIGURE 13: Pulsating-bubble sound power level versus entry kinetic energy.

Section 4.5.1, the power level of the water-entry sound was shown as a function of the kinetic energy. Thus, the bubble radius can be described in terms of kinetic energy (Figure 15). As can be seen from the figure, the minimum radius seems to change from about $0.003 \mathrm{~m}$ to about $0.004 \mathrm{~m}$, which is an increase of about $1 / 3$, hardly constant. An expression for the maximum bubble radius is

$$
R_{\max }=1.65 \times 10^{-2} E_{k}^{1 / 3}-8.24 \times 10^{-4} .
$$
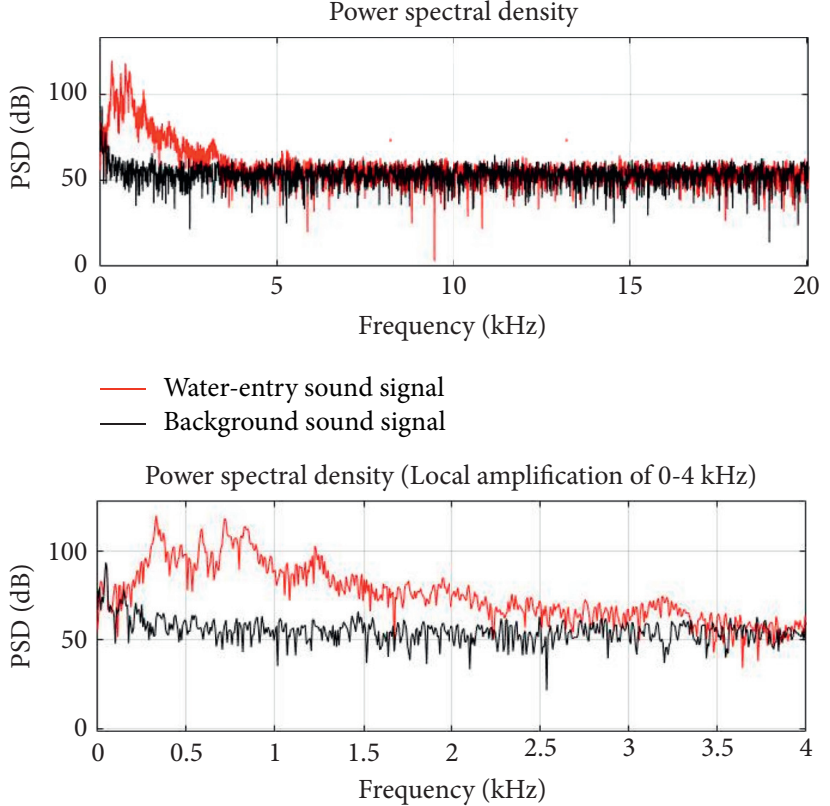

Water-entry sound signal

Background sound signal

FIgUre 14: Pulsating-bubble sound power spectral density. The bottom panel is a magnified version of the area circled in the top panel.

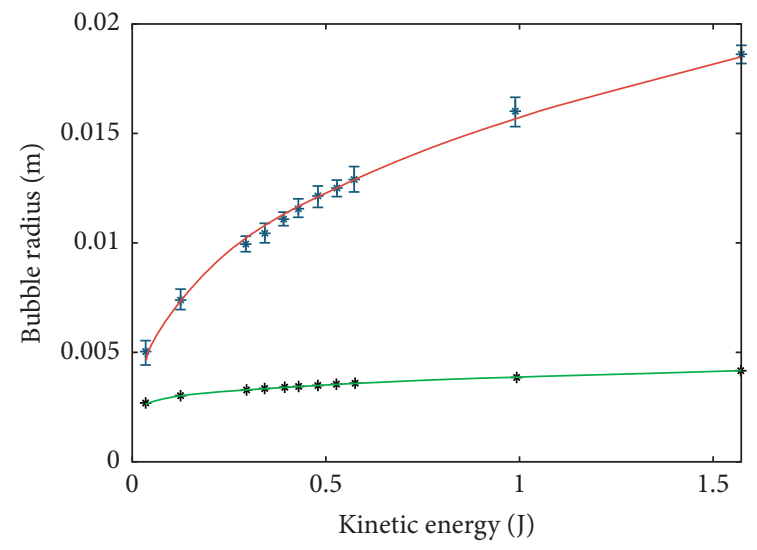

I Maximum Radius

* Minimum Radius

Figure 15: Bubble radius versus kinetic energy.

\section{Discussion and Conclusions}

In this paper, a metal ball, released by a self-developed device, was dropped into a non-anechoic tank. In the near field, the virtual-source method was combined with the time-domain integration method to measure the acoustic power of the metal ball when it entered the water. 
Relations between the water-entry sound power and ball size, entry velocity, and kinetic energy of the metal ball were determined. The theoretical and experimental results show that

(1) Near-field measurements of the water-entry sound of the metal ball in the non-anechoic tank can eliminate the influence of reflected sound so that the characteristics of the water-entry sound can be determined.

(2) In the near field of the sound source, the sound power of a metal ball entering water obtained by the virtual-source method combined with time-domain integration is basically consistent with that obtained by spatial averaging in the far field in a non-anechoic tank. This confirms the accuracy of the method of measuring the transient sound of a metal ball entering water used in this paper.

(3) The contribution of the pulsating-bubble sound to the water-entry sound energy is about 4 orders of magnitude larger than the contribution of the initial impact sound. Both have a low conversion efficiency relative to the water-entry kinetic energy. The kinetic energy mainly remains as kinetic energy since the ball continues to move.

(4) The power levels of the initial impact sound and pulsating-bubble sound are both proportional to the ball size for fixed entry speeds. The power levels of the initial impact sound and the pulsating-bubble sound are proportional to the $2 / 3$ power of the entry velocity for fixed ball size.

(5) An acoustic model of the water-entry sound was established. The sound power level is proportional to the $1 / 3$ power of the kinetic energy. The maximum bubble radius is also proportional to the $1 / 3$ power of the kinetic energy, whereas the minimum bubble radius is almost constant.

(6) The methods applied in this paper could also be used as a reference for other transient sound measurements.

The conclusions of this paper may not apply to largescale objects, and the experimental conditions are limited, such as setting the water height, the ball of the particle size, and density. In addition, we only studied the case of the ball entering water vertically, and whether the angle of the ball entering water and the rotating motion of the ball have influence on the sound power still needs further study, and these can be improved in the future.

\section{Data Availability}

The data used to support the findings of this study are available from the corresponding author upon request.

\section{Conflicts of Interest}

The authors declare that there are no conflicts of interest regarding the publication of this paper.

\section{Acknowledgments}

This research was supported by the National Natural Science Foundation of China (grant 11874131) and by the Stable Support Fund of the Acoustic Science and Technology Laboratory (grant 6142108190110).

\section{References}

[1] L. Chihua and Z. Jijia, "Research on the oblique attitude impact of aerial torpedo falling into water," Chinese Journal Applied Mechanics, vol. 3, pp. 132-137, 1997.

[2] Z. Weiqiang and S. Hui, "Prediction of underwater noise spectrum level under wind and rain conditions," Technical Acoustics, vol. 22, 2011.

[3] L. Shu and S. Dajing, Underwater Noise Characteristics of Rainfall, pp. 394-397, Western China Acoustics Academic Exchange Meeting, Harbin Engineering University, Chengdu, China, 2016.

[4] A. M. Worthington and R. S. Cole, "Impact with a liquid surface studied by the aid of instantaneous photography. paper II," Philosophical Transactions of the Royal Society of London. Series A, Containing Papers of a Mathematical or Physical Character, vol. 194, pp. 252-261, 1900.

[5] H. R. A. Mallock, "Sounds produced by drops falling on water," Proceedings of the Royal Society of London. Series A, Containing Papers of a Mathematical and Physical Character, vol. 95, no. 667, pp. 138-143, 1918.

[6] G. E. Bell, "On the impact of a solid sphere with a fluid surface," The London, Edinburgh, and Dublin Philosophical Magazine and Journal of Science, vol. 48, no. 287, pp. 753-764, 1924.

[7] T. Von Karman, "The impact on seaplane floats during landing," Archive \& Image Library, Chicago, IL, USA, No. 321, 1929.

[8] H. Wagner, "Phenomena associated with impacts and sliding on liquid surfacesÜber Stoß- und gleitvorgänge an der oberfläche von flüssigkeiten," ZAMM - Zeitschrift für Angewandte Mathematik und Mechanik, vol. 12, no. 4, pp. 193-215, 1932.

[9] G. Birkhoff and T. E. Caywood, "Fluid flow patterns," Applied Physics, vol. 20, pp. 60-65, 1949.

[10] A. C. Fairlie-Clarke and T. Tveitnes, "Momentum and gravity effects during the constant velocity water entry of wedgeshaped sections," Ocean Engineering, vol. 35, no. 7, pp. 706-716, 2008.

[11] T. Grumstrup, J. B. Keller, and A. Belmonte, "Cavity ripples observed during the impact of solid objects into liquids," Physical Review Letters, vol. 99, no. 11, Article ID 114502, 2007.

[12] M. Jalalisendi and M. Porfiri, "Water entry of compliant slender bodies: theory and experiments," International Journal of Mechanical Sciences, vol. 149, pp. 514-529, 2017.

[13] J. G. Gao and Z. H. Chen, "Numerical investigations on the oblique water entry of high-speed projectiles," Applied Mathematics and Computation, vol. 362, 2019.

[14] Q. Wang, B. Zhang, and P. Yu, "Numerical investigation on the water entry of several different bow-flared sections," Applied Sciences-Basel, vol. 10, no. 22, 2020.

[15] S. Schedin, A. O. Wåhlin, and P. O. Gren, "Transient acoustic near field in air generated by impacted plates," The Journal of the Acoustical Society of America, vol. 99, no. 2, pp. 700-705, 1996. 
[16] S. Huang and Y. Liang, "Water entry sound detection in strong noise by using the spectrogram matrix decomposition method," Applied Acoustics, vol. 161, Article ID 107171, 2020.

[17] D. Shang, R. Tang, Q. Li, and J. Song, "Measurement of radiated sound power from a complex underwater sound source in a non-anechoic pool based on spatial averaging," Journal of Sound and Vibration, vol. 468, Article ID 115071, 2020.

[18] Z. HE and Y. Zhao, Fundamentals of Acoustics, National Defense Industry Press, Beijing, China, 1981.

[19] R. Tang, X. Yu, D. Shang, and Q. Li, “A new application for reverberation tanks: measurement of underwater impulsive sound characteristics," Measurement Science and Technology, vol. 30, no. 7, Article ID 075006, 2019. 